\title{
Interval valued intuitionistic fuzzy analytic hierarchy process-based green supply chain resilience evaluation methodology in post COVID-19 era
}

\author{
Ertugrul Ayyildiz ${ }^{1,2}$ (])
}

Received: 12 August 2021 / Accepted: 6 October 2021 / Published online: 20 October 2021

(c) The Author(s), under exclusive licence to Springer-Verlag GmbH Germany, part of Springer Nature 2021

\begin{abstract}
Supply chain organizations should calmly and cautiously take the most accurate and sustainable decisions quickly and put them into practice. It is obvious that traditional time series-based demand and supply planning approaches are insufficient to meet current business needs due to factors such as sharp changes in market and commercial dynamics, pandemics, and natural disasters on the management of green supply chains, especially these days. In the near future, there will be a need for more resilient supply chains with a flexible business models that are not affected by sudden changes and that can make sustainable decisions dynamically. Additionally, all stakeholders must act with a green supply chain approach to conduct production and service activities in a way that causes the least damage to nature. Companies must build more resilient supply chains by considering environmental sensitivities to compete in the market and ensure their continuity. In this context, the green supply chains should be evaluated according to their resilience. For this purpose, Supply Chain Operations Reference (SCOR) model is extended with novel performance attributes to evaluate resilience of green supply chains in this study. The SCOR-embedded novel green supply chain resilience evaluation model is structured as a three-level performance attribute hierarchical structure. Then, the model is handled as a multi-criteria decision-making problem to determine importance of the performance attributes. Best Worst Method integrated Interval Valued Intuitionistic Fuzzy Analytic Hierarchy Process is used to determine the importance of performance attributes. Most important performance attributes are determined in each level of hierarchy. According to results, organizational factors play a key role to build more resilient supply chains. Especially, integrated systems are required for supply chain resilience.
\end{abstract}

Keywords COVID-19 · Green supply chain · Resilience · SCOR · Best Worst · IVIF-AHP

\section{Introduction}

Rapid industrialization has depleted natural resources and the emergence of environmental problems. Despite the limited amount of resources, the gradual increase in consumption and the world population and the deterioration of the ecological environment lead consumers, non-governmental organizations, official institutions, governments, and businesses to green

Communicated by Philippe Garrigues.

Ertugrul Ayyildiz

ertugrulayyildiz@ktu.edu.tr

1 Department of Industrial Engineering, Karadeniz Technical University, Merkez Campus, 61080 Trabzon, Turkey

2 Department of Industrial Engineering, Yildiz Technical University, Yildiz Campus, 34349 İstanbul, Turkey thinking in the supply chain. Companies approached the supply chain management with the concept of green thinking and created green supply chain management to effectively manage supply chains considering the environment. While supply chains increase their efficiency and profitability, they also want to create awareness by minimizing their negative effects on the environment with green supply chain management.

Supply chain management is planning, coordinating, executing, and controlling the people and organizations constructing the supply chain, and their activities in line with the ultimate goals of the supply chain (Fox et al. 2001). Supply chain management consists of four main stages: planning, procurement, production, and distribution (Rai et al. 2011). Planning is the management of procurement, production, and demands. Procurement is the supply, storage, and management of production resources (raw materials). The production is the transformation of raw materials into final products. The 
distribution consists of the storage of products, inventory management, customer order management, and delivery to the customer. Supply chain managers should adopt more environmental friendly approaches because of the laws and regulations enacted by governments regarding the recycling of consumed resources, competition conditions, and consumer pressures arising from the increase in environmental awareness. Green supply chain management integrates the environmental dimension with supply chain management by examining the environmental impact of supply chain management processes in stakeholders of supply chain (Yu et al. 2014). From this perspective, managers adopt green supply chain management by transforming their supply chains into a more environmentally friendly structure to design less polluting production systems, minimize their waste, manage environmental risks, and act with social responsibility awareness.

Green supply chains are differentiating from traditional supply chains by their integration with an environmentalist approach. Green practices are essential elements of green supply chain management (Sarkis 2003). With green practices, faster action can be taken, high flexibility is provided, and environmental factors are prioritized in supplier selection and logistics activities, and resources are used effectively. Therefore, while purchasing the raw materials and supplies required for production in the green supply chain, raw materials and supplies that cause the least harm to the environment are preferred, and the environmental impacts that occur during the production and transportation of these raw materials and supplies are minimized.

Green supply chain management protects the environment. The main purpose is to purify logistics and supply chain activities and the value process created for each service from the negative effects of all kinds of wastes such as excessive resource use, excessive carbon emissions, chemicals, and hazardous materials. Effective green supply chain management can reduce the environmental impacts of industrial activities, and while doing this, it also considers factors such as quality, cost, energy efficiency, and supply chain resilience. Resilience must be taken into consideration while developing environmental sustainability strategies because of organizational goals (Mohammed 2020). Resilience leads to more stable supply chains (Rajesh 2021). Supply chain resilience plays a key role in shifting companies toward engaging in both environmental management and sustainable development ( $\mathrm{Ji}$ et al. 2020). Resilience and environmental concern dimensions need to be addressed simultaneously in supply chain management (Mohammed 2020). Thus, the supply chain both complies with environmental concerns and increases its long-term total profit. Long-term supply chain performance can be developed by considering competitive advantages of resilience and the integration of greenness with resilience for green supply chains (Mahmoudi et al. 2021). Additionally, the strategy is critical as the ultimate goal of the enterprises is continuity and long-term profit. Companies should focus and develop supply chain management to gain a competitive advantage in the market. At this point, supply chain resilience becomes more important.

Supply chain resilience can be briefly defined as the strength of the supply chain to be affected by unexpected changes at the minimum level, to resist crises and to maintain its continuity despite changes. The continuity of the supply chain is directly related to the resilience of companies. Companies with high resilience contribute to constructing a more resilient supply chain and ensure the longevity of supply chain. Supply chain resilience becomes more important to cope with sudden variations, in the era of COVID-19 (SARS-Cov-2) pandemic (Barbieri et al. 2020).

The COVID-19, which first appeared in Wuhan, China, and has recently spread worldwide, creates a deep concern worldwide with the pressure in international markets and high case numbers and death rates in all countries (Ayyildiz and Taskin Gumus 2021a). The epidemic caused economic fluctuations around the world which affected green supply chains as well as all supply chains. Supply disruptions and demand shocks due to the pandemic may cause global reactions. With the COVID-19 pandemic, 2020 has been a period in which supply chain risk management has emerged effectively. Various countries and companies have taken different measures and taken protective steps, but they have been insufficient. The difficulties experienced in supply chain management over the years can be summarized as demand, supply, stability of the distribution channel, employee scarcity, instant order tracking, geopolitical stagnation, free trade, supply chain permanence, and stable financial flow. With the COVID-19 pandemic, all these difficulties have arisen immediately, and supply chains have been broken at many points.

The COVID-19 has highlighted the environmental practices of green supply chains by emphasizing the importance of sustainable production and consumption. Management of green supply chain risks, preventing vulnerability and enhancing supply chain resilience, is essential in situations such as this pandemic and disaster. Supply chain resilience is affected by many factors. Depending on the changing demands of end consumers, these factors can change constantly. For example, consumers pay more attention to the environmental sensitivity of companies recently. So, supply chain resilience is expected to be associated with environmental-friendly activities. Additionally, governments also implement practices in green supply chain activities, and as a result of these practices, supply chains that support the green approach become more advantageous over their competitors. Proactive implementations need to be adopted for securing supply chain systems by handling core vulnerabilities of supply chain (Rajesh 2020). 
As a result of literature review, the following observations motivated this study. Evaluating resilience of green supply chains is not considered with comprehensive analysis in the current literature. A complete and detailed set of criteria for evaluating resilience of green supply chain is not studied in the supply chain literature. Furthermore, the COVID-19 effect on green supply chain management with respect to resilience of supply chain is not analyzed. Also, the resilience performance evaluation model for green supply chain is not seen in the literature. Hence, in this study, we present Supply Chain Operations Reference (SCOR)-embedded resilience evaluation model for the first time in the literature. This study aims to determine importance of performance attributes related to green supply chain resilience unlike the supplier selection literature. A hybrid decision-making methodology using BWM and IVIF-AHP is presented to understand effects of criteria on resilience in green supply chains. In this study, we focus on these gaps in the supply chain literature, and aim to answer the following research questions: (i) How can the SCOR model be extended to assess green supply chain resilience? (ii) Which factors are effective in the green supply chain resilience? (iii) What are the most important performance attributes on green supply chain resilience?

In this study, we evaluate the resilience of green supply chains in post COVID-19 era. We improve SCOR model with two novel level 1 performance attributes to meet green supply chains' requirement in today's world. The green supply chain resilience evaluation model is constructed as a three-level hierarchical structure to determine the resilience of supply chains. This model is handled as a MCDM problem. The inner levels of performance attributes are also presented in this study to make a more comprehensive evaluation. Importance weights of performance attributes for each level of structure are determined via Best Worst Method (BWM)-integrated Interval Valued Intuitionistic Fuzzy AHP (IVIF-AHP) methodology based on expert opinions.

According to a detailed MCDM literature review based on intuitionistic fuzzy sets, no study integrates IVIF-AHP with BWM. Therefore, we propose a novel solution approach involving BWM-integrated IVIF-AHP, which is developed for the first time to solve criteria weighting in MCDM problems. In addition, using the SCOR-embedded model for the first time for evaluating green supply chain resilience is one of the innovations of this study. Therefore, this study stands out in terms of both methodological and application novelties.

This study is organized as follows: Literature review about green supply chain is given in the "Related studies" section. The "The SCOR-embedded resilience evaluation model" section gives the proposed green supply chain resilience evaluation model. BWM-integrated IVIF-AHP methodology is explained with details in the "Proposed methodology" section. The "The weight determination" section presents the application of the proposed methodology to determine importance weight of performance attributes. Practical implications of this study are explained in the "Practical implications" section. The last section summarizes the conclusions and future directions of the study.

\section{Related studies}

Green supply chain management and resilience of green supply chains are hot topics among researchers and academicians for a long time. Especially, in the last years, researchers include both resilience and greenness for supply chains to develop strategies for supply chain management. According to reviewed studies, it can be said that resilience factors must be included in evaluation models to construct more sustainable green supply chains. Also, green supply chain resilience-based studies usually focus on supplier selection. These studies evaluate different specific supply chains. Some remarkable studies are summarized as follows.

Ahi and Searcy (2013) analyze definitions for both green and sustainable supply chain management. Twenty-two definitions are identified for green supply chain management. They emphasize the resilience focus as one of the seven characteristics of business sustainability (Ahi and Searcy 2013). Business sustainability should be supported with the creation of resilient organizations throughout whole supply chains through integrated social, financial, and environmental systems (Bansal 2010). Mari et al. (2014) develop goal programming model to optimize cost by considering supply chain resilience and sustainability. Rauer and Kaufmann (2015) focus on capabilities of green supply chains and emphasize resilience capabilities as one of three dynamic capabilities. Malek et al. (2017) develop a model to evaluate green supply chain resilience. Gray relational analysis is utilized to prioritize the criteria in the evaluation model. Tseng et al. (2018) analyze green supply chain management by MCDM-based methodology, and find resilience is one of the top-weighted aspect for long-term perspective. Fahimnia et al. (2018) examine the supply chain strategies. They show that green and resilient strategies are costly, but more resilient supply chains have long-term benefits, so building robust green supply is a good investment. Das and McClung (2020) propose a green and resilient supply chain design model that incorporates green practices with resilience planning for supply chain strategies. Elzarka (2020) uses lean, agile, resilient, and green (LARG) index to assess the leanness, agility, resilience, and greenness of fast-moving consumer goods supply chain in Egypt. The gaps and improvement opportunities for green supply chains are also highlighted. Xiong et al. (2020) focus on supplier selection problem. To determine the best supplier 
considering resilience and greenness, a hybrid MCDM method is utilized. Ramirez-Peña et al. (2020) emphasize the green supply chain paradigm connected to social aspects and resilience is one of the intrinsic factors of the shipbuilding supply chain. Mohammed (2020) explore the requirements and complementarities for resiliency and greenness in supply chains, specify the criteria for resiliency and greenness, and propose MCDM approach to solve the supplier selection problem with respect to resiliency and greenness. Trivellas et al. (2020) focus on green supply chain management implications for sustainable supply chain performance. Ji et al. (2020) analyze the roles of resilience and knowledge combination of supply chain in terms of the green supplier integration. Zavala-Alcívar et al. (2020) present a literature review to examine supply chain resilience and its effects on the supply chain sustainability. Negri et al. (2021) review the supply chain management literature in terms of sustainability and resilience and summarize the future research topics. Ghomi-Avili et al. (2021) design competitive green supply chain to construct more resilient supply chains using bi-level supply chain network design model. Sachin and Rajesh (2021) examine the sustainable supply chain practices' effects on financial performance of supply chains.

Supply chain resilience and green supply chain management are well-studied topics among researchers, though there are a limited number of studies that especially focus on green supply chain resilience, especially post COVID-19 era. Therefore, the green supply chain resilience evaluation model is proposed in this study. SCOR performance evaluation model is extended with novel performance attributes to construct the proposed model. Besides, three levels of performance attributes are defined and evaluated. To determine the weight of each performance attribute, the model is handled as a hybrid MCDM problem apart from previous works.

\section{The SCOR-embedded resilience evaluation model}

The supply chain is an organization with international components from different cultures. Supply chain management is a complex organizational process that needs synchronization of activities between stakeholders (Zimon and Madzík 2020). Therefore, the standard business model that can be used in every national or international supply chains is required. For this purpose, the Supply Chain Council presented the SCOR model to be used in supply chains to improve their effectiveness and to provide a process-based supply chain management strategies (Lockamy and Mccormack 2004). The SCOR model is an integrated business model presented with the understanding of supply chain management in line with these requirements. SCOR is the first reference model to be recognized as the cross-industry standard to perform effective supply chain management. SCOR is a set of best practices and benchmarking tools that help organizations improve their processes and gain a competitive advantage. It also references a model developed to be an industry standard. SCOR model is useful tool to describe activities of supply chains in operations management for both practice alike and research (Ayyildiz and Taskin Gumus 2021b). The model provides meaningful results to analyze the supply chain performance (Müller 2019). The model is continuously updating and detailing according to the needs of supply chains. Specifying the implemented processes in supply chains is required to create effectively an integrated management system (Zimon et al. 2020).

Metrics and performance attributes are the main components of the SCOR reference model's performance part. Metrics are a standard measurement tool to determine the ability of supply chain to achieve strategies. Performance attributes are a group of metrics to determine and explain strategies and they cannot measure themselves. There are five key performance attributes in SCOR model which are reliability, flexibility, responsiveness, costs, and assets. Using at least one metric for each attribute is recommended to ensure a more accurate and balanced governance by the Supply Chain Council (Ntabe et al. 2015). The supply chain performance evaluation should consider each of the components of supply chain from the warehouse of raw material to the point of end customer.

Performance attributes in the traditional SCOR model are determined according to the traditional supply chains' needs. Due to the rapid changes that have occurred in the especially last two decades, the effective supply chain management has become more challenging and competitive. This has prompted many companies to adopt modern supply chain management strategies (Mohammed 2020). The supply chain concept can be used as an effectively assisting approach in decision-making and planning for highly complex industries (Baghizadeh et al. 2021). Supply chain management means effective and unproblematic approach and coordination of tangible and intangible flows between all stakeholders toward the ultimate goals of the supply chain, such as maximizing profits, customer satisfaction, and minimizing costs (Mohammed et al. 2021).

There are radical changes in the structure of supply chains as a result of globalization. So the supply chains have faced several changes and developments that make supply chains encounter new challenges (Mohammed 2020). Supply chains have become more vulnerable to disruptions because of strategic sourcing and globalization (Mohammed et al. 2021). Hence, the modern supply chains should be adopted to cope with these challenges to survive in the highly challenging market. Relationships between companies on the supply chain network are handled by the concept of supply chain integration. Managers should perform external supply chain 
integration by harmonizing external activities with their own business activities (Beheshti et al. 2014). The one purpose of supply chain integration is to increase supply chain resilience.

Supply chain resilience plays an important role in the success of stakeholders and supply chains (Tukamuhabwa et al. 2015). Reducing the effects of risks on the supply chain and ensuring that the damage is repaired by responding with an acceptable time are among the most important benefits of supply chain resilience. Supply chain resilience can also be defined as an ability to overcome bottlenecks, power to overcome risks, and taking effective measures against risks. Increasing the resilience of the supply chain not only improves the cooperation between the partner companies in the supply chain, but also enables them to adapt to the changing conditions.

Risk management should be approached from a holistic perspective. Risk management is not only concerned with managing external risks but also focusing on the risks that can be created by the supply chain within itself; on the other hand, it should also cover the risks within the whole supply chain. Agile supply chains are more resilient to risks. Agility means reconfiguring the system quickly against predictable changes (Bernardes and Hanna 2009). Companies act with less agility when any change in customer demands exposes their suppliers to operational risk. Namely, low agility levels do not just affect themselves; they affect suppliers as well. Therefore, agility is an important concept for the supply chain.

Renewal of green supply chain management in today's challenging market, especially in the post COVID-19 era, is important to provide the continuity of supply chain. In this context, the performance of green supply chain should be evaluated in terms of resilience strategies. To make a comprehensive evaluation, the traditional SCOR model should be extended with respect to environmental concerns. For this purpose, new key performance attributes should be taken into consideration to make a more accurate supply chain resilience evaluation. All performance attributes should be elaborated in terms of green supply chain while evaluating the resilience of the supply chain. In this study, the new resilience-based performance attributes are determined and new attributes are integrated into the SCOR model. Namely, Organizational and Environmental are considered new performance attributes in the novel SCOR-embedded green supply chain resilience evaluation model proposed in this study. The novel resilience evaluation model is structured as a three-level hierarchical performance attribute structure to make a more detailed, holistic, and comprehensive green supply chain resilience evaluation model. The inner performance attributes are determined considering green supply chain resilience by both literature review and expert opinions. The SCOR-embedded green supply chain resilience evaluation model and its level 2 performance attributes are presented in Fig. 1.

The resilience evaluation model includes seven different level 1 performance attributes. "Organizational" an "Environmental" are novel attributes added to the traditional SCOR model to encounter green supply chain needs.

Reliability (PA-1) The performance of the supply chain in delivery is to deliver the right product at the right place, at the right time, in the right condition and packaging, with the right quality and the right document.

Flexibility (PA-2) The ability of the supply chain to respond to changes in the market to gain competitive advantage or to maintain enhance its competitiveness.

Responsiveness (PA-3) The delivery speed of supply chain in providing products to customers.

Cost (PA-4) Costs related to the stage of the supply chain.

Assets (PA-5) Supply chain efficiency of managing whole organization's assets to meet demand.

Organizational (PA-6) Organizational capabilities to increase the resilience of the supply chain by taking a holistic approach.

Environmental (PA-7) Environmental impact of the supply chain and approach to addressing environmental issues.

Level 3 performance attributes are determined based on literature review. These attributes, which form the basis of our study to evaluate green supply chain resilience, are frequently used factors in previous studies based on supply chain resilience and/or green supply chain. Table 1 presents level 3 attributes and the studies that use level 3 performance attributes and their derivatives.

\section{Proposed methodology}

A three-level performance attribute hierarchy is constructed on the basis of SCOR model to determine importance of attributes to construct more resilient green supply chains. First, the BWM is employed by experts' evaluation to determine weights of level 1 attributes. BWM is used in this stage, because of the higher number of level 1 performance attributes. Then, IVIF-AHP is employed to determine the weights of both level 2 and level 3 performance attributes. 
Fig. 1 Performance attributes for green supply chain resilience

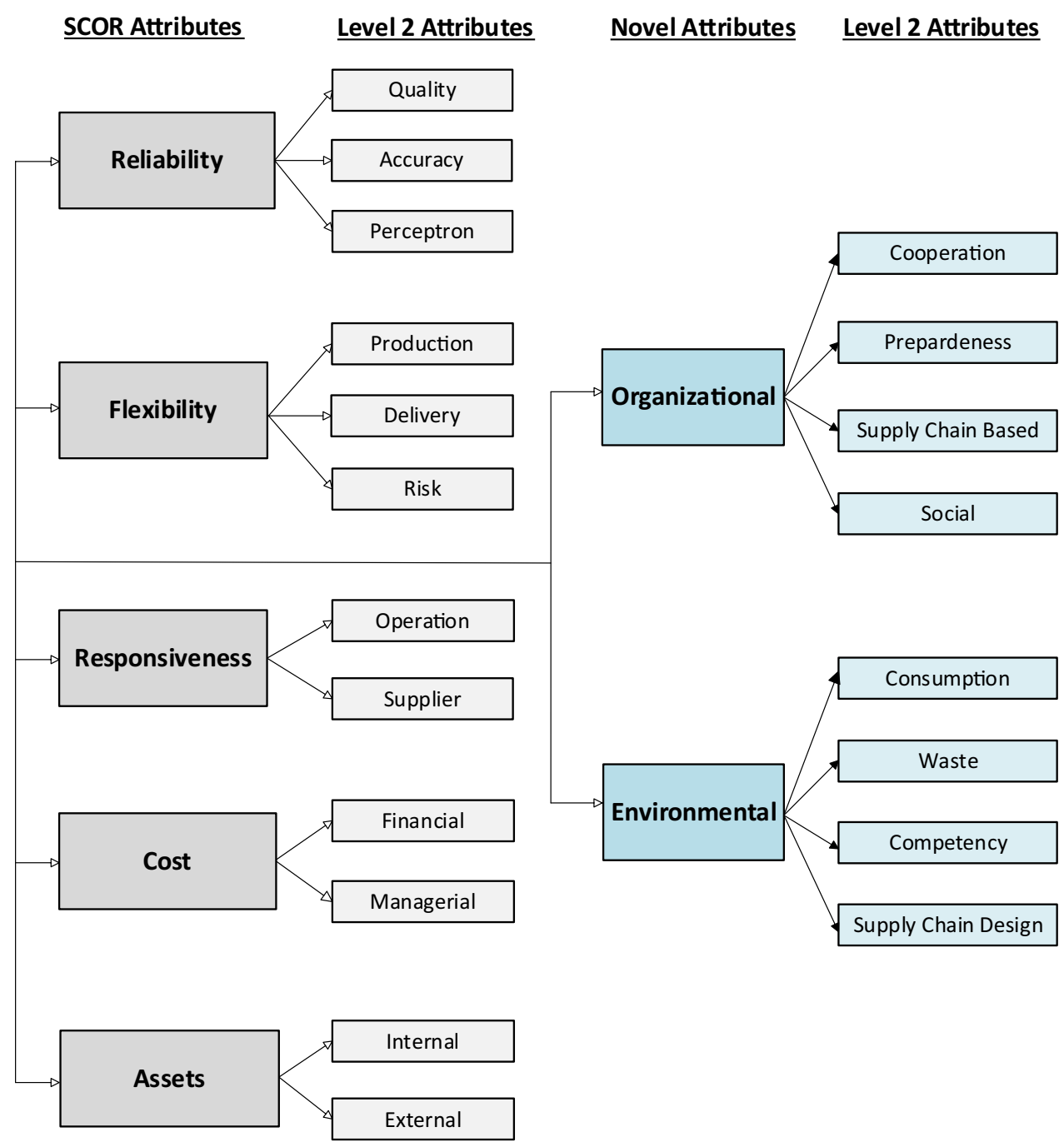

The flow of the proposed hybrid decision-making methodology is given in Fig. 1.

\section{Best Worst Method}

Rezaei (2015) developed the BWM as a powerful MCDM technique to solve complex decision-making problems. After, the BWM is widely employed to determine the criteria weights (Chen et al. 2020). BWM needs less pairwise comparison than similar pairwise comparison-based techniques, such as AHP and ANP (Ecer 2021). Hence, BWM provides convenience to the decision-maker and more consistent comparisons by reducing the number of pairwise comparisons (Luo et al. 2021). The method becomes prominent with computation time and robustness of algorithm. BWM provides more accurate and reliable results than AHP (Chen et al. 2020). BWM is utilized by many researchers to handle different problems. Ecer (2021) utilize BWM to make sustainability assessment of onshore wind plants. Chen et al. (2020) use BWM-integrated TOPSIS to analyze critical barriers for e-waste management systems. Tavana et al. (2021) propose hierarchical fuzzy BWM to determine weights of criteria to solve a sustainable supplier selection problem. Ayyildiz and Taskin Gumus (2021a, b) extend the SCOR model with two novel metrics related to the digitalization and first-level metrics are weighted by BWM. Huang et al. (2021) propose a Bayesian BWM and modified Ranking Organization Method for Enrichment Evaluations (PROMETHEE)-based airport resilience assessment model. Sen et al. (2021) examine the flood resilience of housing infrastructure system by BWM. Moslem et al. (2020) employed BWM to examine mobility choice alternatives for post COVID-19 era. The detailed steps of BWM are given below (Kheybari et al., 2019):

Step1: The best (most important) and the worst (least important) criteria are determined.

Step3: Best-to-Others vector is constructed. The level of importance of the best criterion among each criterion is determined between 1 and 9 . While 9 means the best criteria are absolutely more important than the other cri- 
Table 1 Level 3 performance attributes and their sources

\begin{tabular}{|c|c|}
\hline Performance Attribute & Sources \\
\hline 1.1.1 Quality Assurance & (V. Parkouhi and S. Ghadikolaei 2017; Das et al. 2021) \\
\hline 1.1.2 Service Quality & (Sharma and Joshi 2020; Das et al. 2021) \\
\hline 1.1.3 Product Quality & (Wang et al. 2016, 2017; Hosseini and Khaled 2019; Shafiee et al. 2021) \\
\hline 1.2.1 Scrap Quality & (V. Parkouhi and S. Ghadikolaei 2017; Mohammed et al. 2021) \\
\hline 1.2.2 Defective Rate & (Viswanadham and Samvedi 2013; Tramarico et al. 2017; Wang et al. 2017) \\
\hline 1.2.3 Delivery Performance & (Mohammed 2020; Pulansari and Putri 2020; Fallahpour et al. 2021) \\
\hline 1.2.4 Turnover & (Alnaggar and Bhanot 2018; Al-Haidous and Al-Ansari 2020; Fallahpour et al. 2021) \\
\hline 1.3.1 Trust & (V. Parkouhi and S. Ghadikolaei 2017; Mohammed et al. 2021) \\
\hline 1.3.2 Overall Reputation & (Mohammed 2020; Pamucar et al. 2020) \\
\hline 2.1.1 Flexible Manufacturing System & (Namdar et al. 2021) \\
\hline 2.1.2 Production Mix Flexibility & (V. Parkouhi and S. Ghadikolaei 2017; Wang et al. 2017) \\
\hline 2.1.3 Adaptive Capability & (Pramanik et al. 2017) \\
\hline 2.1.4 Capacity Flexibility & (Haldar et al. 2012; V. Parkouhi and S. Ghadikolaei 2017; Rajesh 2020) \\
\hline 2.2.1 Contract Flexibility & (Namdar et al. 2021) \\
\hline 2.2.2 Time Flexibility & (Wang et al. 2017) \\
\hline 2.3.1 Risk Oversight & (Mohammed et al. 2021; Namdar et al. 2021) \\
\hline 2.3.2 Risk Management & (V. Parkouhi and S. Ghadikolaei 2017; Fallahpour et al. 2021; Namdar et al. 2021) \\
\hline 2.3.3 Risk Reduction & (Rajesh and Ravi 2015; Malek et al. 2017; Wang et al. 2017) \\
\hline 3.1.1 Operating Capacity & (Wang et al. 2016; V. Parkouhi and S. Ghadikolaei 2017; Mohammed et al. 2021) \\
\hline 3.1.2 Operating Time & (Pramanik et al. 2017) \\
\hline 3.1.3 Operation Agility & (Malek et al. 2017; Arabsheybani and Arshadi Khasmeh 2021; Mohammed et al. 2021) \\
\hline 3.2.1 Lead Time & (Hosseini and Khaled 2019; Pulansari and Putri 2020; Rajesh 2020; Mohammed et al. 2021) \\
\hline 3.2.2 Location & (Viswanadham and Samvedi 2013; Wang et al. 2017; Mohammed et al. 2021) \\
\hline 4.1.1 Purchasing Cost & (Al-Haidous and Al-Ansari 2020; Das et al. 2021; Mohammed et al. 2021) \\
\hline 4.1.2 Product(ion) Cost & (Wang et al. 2016, 2017; Pramanik et al. 2017) \\
\hline 4.1.3 Operational Cost & (Al-Haidous and Al-Ansari 2020) \\
\hline 4.1.4 Transportation Cost & (Al-Haidous and Al-Ansari 2020) \\
\hline 4.2.1 Cost Optimization & (Tseng et al. 2018; Hosseini and Khaled 2019; Sharma and Joshi 2020) \\
\hline 4.2.2 Ethical Pricing & (Das et al. 2021) \\
\hline 4.2.3 Financial Stability & (Sharma and Joshi 2020; Pamucar et al. 2020) \\
\hline 5.1.1 Process Automation & (Das et al. 2021; Namdar et al. 2021) \\
\hline 5.1.2 Technology Level & (Rajesh and Ravi 2015; Malek et al. 2017; Rajesh 2020; Namdar et al. 2021) \\
\hline 5.1.3 Strategic Stock & (Haldar et al. 2012; Foroozesh et al. 2019; Rajesh 2020; Namdar et al. 2021) \\
\hline 5.1.4 Emergency Order & (V. Parkouhi and S. Ghadikolaei 2017; Wang et al. 2017; Sabouhi et al. 2018) \\
\hline 5.2.1 Redundant Supplier & (Torabi et al. 2015; Malek et al. 2017; Mohammed et al. 2021; Namdar et al. 2021) \\
\hline 5.2.2 Outsourcing & (Torabi et al. 2015; Das et al. 2021) \\
\hline 5.2.3 Multiple Sourcing & (Torabi et al. 2015; Wang et al. 2016; Sabouhi et al. 2018; Namdar et al. 2021) \\
\hline 6.1.1 System Integration & (Rajesh 2020) \\
\hline 6.1.2 Collaboration & (Malek et al. 2017; Sharma and Joshi 2020; Fallahpour et al. 2021) \\
\hline 6.1.3 Information Sharing & (Sharma and Joshi 2020) \\
\hline 6.2.1 Disaster Planning & (Rajesh 2020; Das et al. 2021) \\
\hline 6.2.2 Pandemic Planning & (Rajesh 2020; Das et al. 2021) \\
\hline 6.2.3 Strategic Fit & (V. Parkouhi and S. Ghadikolaei 2017) \\
\hline 6.2.4 Forecast Accuracy & (Al-Haidous and Al-Ansari 2020) \\
\hline 6.3.1 Leanness & (Arabsheybani and Arshadi Khasmeh 2021) \\
\hline 6.3.2 Visibility & (Viswanadham and Samvedi 2013; Fallahpour et al. 2021; Mohammed et al. 2021) \\
\hline 6.3.3 Supply Chain Knowledge & (V. Parkouhi and S. Ghadikolaei 2017) \\
\hline 6.3.4 Supply Chain Complexity & (Haldar et al. 2012; Khemiri et al. 2017) \\
\hline 6.4.1 Political Support & (Viswanadham and Samvedi 2013; Wang et al. 2017; Das et al. 2021) \\
\hline 6.4.2 Training and Education & (Sen et al. 2016; Al-Haidous and Al-Ansari 2020; Pamucar et al. 2020) \\
\hline
\end{tabular}


Table 1 (continued)

\begin{tabular}{ll}
\hline Performance Attribute & Sources \\
\hline 6.4.3 Social Responsibility & (Tseng et al. 2018; Shafiee et al. 2021) \\
7.1.1 Energy Consumption & (Tramarico et al. 2017; Wang et al. 2017; Pulansari and Putri 2020) \\
7.1.2 Raw Material Consumption & (Al-Haidous and Al-Ansari 2020) \\
7.1.3.Recycling Material & (Tramarico et al. 2017; Tseng et al. 2018; Pulansari and Putri 2020) \\
7.2.1 Waste Management & (Tramarico et al. 2017; Tseng et al. 2018; Mohammed 2020) \\
7.2.2 Pollution Production & (Wang et al. 2017; Al-Haidous and Al-Ansari 2020; Fallahpour et al. 2021) \\
7.2.3 Hazardous Material & (Tseng et al. 2018; Pulansari and Putri 2020; Fallahpour et al. 2021) \\
7.3.1 Environmental Management Sys & (Sen et al. 2016; Tseng et al. 2018; Mohammed 2020) \\
7.3.2 Safety Competencies & (Malek et al. 2017) \\
7.3.3 Environmental Certificate & (Sen et al. 2016; Tseng et al. 2018; Pulansari and Putri 2020; Fallahpour et al. 2021) \\
7.4.1 Environmental Design & (Sen et al. 2016; Wang et al. 2017; Shafiee et al. 2021) \\
7.4.2 Land Usage & (Shafiee et al. 2021) \\
7.4.3 Reverse Logistics & (Tseng et al. 2018) \\
\hline
\end{tabular}

terion, 1 means there is equal importance between the two criteria:

$A_{B}=\left(a_{B 1}, a_{B 2}, \ldots, a_{B n}\right)$ where $a_{B j}$ shows the level of importance of the best criterion $B$ over criterion $j$. Let $n$ be the number of criteria.

Step4: Others-to-Worst vector is constructed. Level of importance of each criterion over the worst criterion is determined between 1 and 9:

$A_{w}=\left(a_{1 W}, a_{2 W}, \ldots, a_{n W}\right)^{T}$ where $a_{j W}$ shows the level of importance of the criterion $j$ over the worst criterion $W$.

Step5: The optimal weights of the criteria $\left(w_{1}^{*}, w_{2}^{*}, \ldots, w_{n}^{*}\right)$ are calculated. For each pairwise comparison of $\frac{w_{B}}{w_{j}}$ and $\frac{w_{j}}{w_{W}}$, the values of $\frac{w_{B}}{w_{j}}=a_{B j}$ and $\frac{w_{j}}{w_{W}}=a_{j W}$ are determined.

The main purpose is to find the optimal weights to compute maximum absolute value of $\left|\frac{w_{B}}{w_{j}}-a_{B j}\right|$ and $\left|\frac{w_{j}}{w_{W}}-a_{j W}\right|$ for all $j$ is minimized. Non-negativity constraints (2) and the constraint for the sum of all criteria weights (3) are added to solve the following problem:

$$
\operatorname{minmax}_{j}\left\{\left|\frac{w_{B}}{w_{j}}-a_{B j}\right|,\left|\frac{w_{j}}{w_{W}}-a_{j W}\right|\right\}
$$

subject to

$w_{j} \geq 0$, for all $j$

$\sum_{j=1}^{n} w_{j}=1$

This mathematical model can be represented:

$\min \zeta$

subject to:
$\left|\frac{w_{B}}{w_{j}}-a_{B j}\right| \leq \zeta$, for all $j$

$\left|\frac{w_{j}}{w_{W}}-a_{j W}\right| \leq \zeta$, for al $l j$

The optimal weights of criteria $\left(w_{1}^{*}, w_{2}^{*}, \ldots, w_{n}^{*}\right)$ and $\zeta$ are determined by the mathematical model. $\zeta$ is the consistency of the mathematical model. It is concluded that the comparisons are less reliable and their consistency is weak as the value increases.

\section{IVIF-AHP}

AHP is first developed and presented in the literature by Saaty (1988) and became one of the most used methods to solve MCDM problems. AHP helps decision-makers to rationally rank and select complex problems (Ikram et al. 2020a). Complex MCDM problems can be broken down into simpler problem structures via AHP (Solangi et al. 2019b). The method examines consistency in expert judgments. AHP sometimes does not provide effective solutions to deal with the uncertainty and fuzziness in expert's subjective judgments, despite its popularity in the literature and ease of use (Büyüközkan and Güleryüz 2016). Fuzzy set theory, which handles uncertainties, can be used to alleviate this disadvantage (Ikram et al. 2020b). Using fuzzy numbers to reflect subjective judgments of experts into decision-making process can help the user. In this study, we determine weights of level 2 and level 3 criteria by fuzzy logic. For this purpose, IVIF sets are used to handle linguistic variables in decisionmaking process. Therefore, IVIF-AHP is used to determine the sub-criteria weights. 
The use of AHP method with intuitionistic fuzzy sets has attracted the attention of many researchers and has subsequently been applied to many application areas. In this section, the literature related to the adopted methodology is reviewed. Some remarkable articles based on AHP with intuitionistic fuzzy sets are given in Table 2 .

The usage of intuitionistic fuzzy sets in MCDM methodologies is introduced to the literature in the 2009. After that, researchers employ AHP under intuitionistic fuzzy environment for different subjects. The first related article is published in 2009. The annual distribution of articles using AHP based on intuitionistic fuzzy sets reviewed can be seen in Fig. 2.

According to Fig. 2, it can be said that the number of articles increases every year. The first article is published in 2009 , followed by just one article for the next 6 years except 2010. Two articles are published in 2016, then the number of articles published increases, six articles are published in 2018, 2019, and 2020. Four articles are published in the first half of 2021.

Atanassov proposed the intuitionistic fuzzy sets as a generalized version of fuzzy sets. Intuitionistic fuzzy sets consist of both membership and non-membership functions, while Zadeh's theory includes only membership function (Ayyildiz and Taskin Gumus 2021b). The sum of membership and nonmembership functions must be between 0 and 1 . The hesitancy

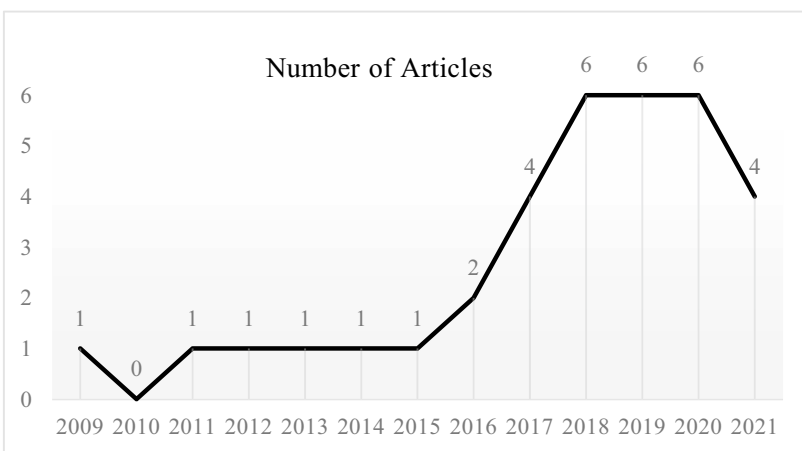

Fig. 2 The number of articles used AHP with on intuitionistic fuzzy sets for years

degree is determined by subtracting the sum of membership and non-membership functions from 1 .

Definition 1: Intuitionistic fuzzy set $\tilde{I}$ in given fixed set $X$ can be given by:

$\tilde{I} \cong\left\{x, \tilde{I}\left(\mu_{\tilde{I}}(x), v_{\tilde{I}}(x)\right) ; x \in X\right\}$

$\mu_{\tilde{I}}(x): X, v_{\tilde{I}}(x): X \mapsto[0,1]$ defines the membership and non-membership of the element $x \in X$ to $\tilde{I}$ respectively.

$0 \leq \mu_{\tilde{I}}(x)+v_{\tilde{I}}(x) \leq 1 ; x \in X$

Table 2 The articles reviewed based on AHP with intuitionistic fuzzy sets

\begin{tabular}{|c|c|c|c|}
\hline Source & Subject & Source & Subject \\
\hline (Sadiq and Tesfamariam 2009) & Drilling fluid selection & (Hinduja and Pandey 2018) & $\begin{array}{l}\text { Healthcare waste treatment alterna- } \\
\text { tives evaluation }\end{array}$ \\
\hline (Wang et al. 2011) & Methodology presentation & (Zhixiong et al. 2019) & Network access selection \\
\hline (Zhang and Huang 2012) & Warning index selection & (Karasan 2019) & Investment alternatives prioritization \\
\hline (Wu et al. 2013) & Methodology presentation & (Büyüközkan et al. 2019) & Hazardous waste carrier selection \\
\hline (Xu and Liao 2014) & Supplier selection & (Dogan et al. 2019) & Corridor selection \\
\hline (Bali et al. 2015) & Personnel promotion & (Taherkhani et al. 2019) & $\begin{array}{l}\text { Kidney allocation criteria prioritiza- } \\
\text { tion }\end{array}$ \\
\hline (Tavana et al. 2016) & $\begin{array}{l}\text { Outsource reverse logistics firm } \\
\text { evaluation }\end{array}$ & (Hinduja and Pandey 2019) & Methodology presentation \\
\hline (Büyüközkan and Güleryüz 2016) & $\begin{array}{l}\text { Product development partner selec- } \\
\text { tion }\end{array}$ & (Kahraman et al. 2020) & Outsource manufacturers evaluation \\
\hline (Tooranloo and Iranpour 2017) & Supplier selection & (Büyüközkan et al. 2020) & Digital service quality evaluation \\
\hline (Nirmala and Uthra 2017) & Online shopping website evaluation & (Murat Ar et al. 2020) & Logistics operations evaluation \\
\hline (Otay et al. 2017) & $\begin{array}{l}\text { Healthcare institutions performance } \\
\text { evaluation }\end{array}$ & (Zahar Djordjevic et al. 2020) & Performance evaluation \\
\hline (Sun et al. 2017) & Web service selection & (Seker and Aydin 2020) & Transportation system evaluation \\
\hline (Tooranloo et al. 2018) & Supplier selection & (Karaşan et al. 2020) & Charging station site selection \\
\hline (Cebi and Ilbahar 2018) & Warehouse risk assessment & (Li and Zhang 2021) & Customer satisfaction \\
\hline (Ouyang and Guo 2018) & $\begin{array}{l}\text { Municipal wastewater treatment } \\
\text { project selection }\end{array}$ & (Yu et al. 2021) & Credit risk analysis \\
\hline (Beskese et al. 2018) & Performance management & (Verma and Chandra 2021) & Security attributes evaluation \\
\hline (Karasan et al. 2018) & Production strategies prioritization & (Shekari et al. 2021) & Tourism dimensions prioritization \\
\hline
\end{tabular}


The degree of hesitancy is calculated:

$\pi_{\tilde{I}}(x)=\sqrt{1-\mu_{\tilde{I}}(x)+v_{\tilde{I}}(x)}$

In this study, interval valued fuzzy numbers are employed to handle the fuzziness and vagueness better.

Definition 2. An IVIF number $\tilde{\alpha}$ is defined in $X$ (Karasan et al. 2018):

$\tilde{\alpha}=\left\{\left\langle x\left[\mu_{\tilde{I}}^{-}(x), \mu_{\tilde{I}}^{+}(x)\right],\left[v_{\tilde{I}}^{-}(x), v_{\tilde{I}}^{+}(x)\right]\right\rangle ; x \in X\right\}$

where

$0 \leq \mu_{\tilde{I}}^{-}(x), \mu_{\tilde{I}}^{+}(x), v_{\tilde{I}}^{-}(x), v_{\tilde{I}}^{+}(x) \leq 1$

$\mu_{\tilde{I}}^{-}(x) \leq \mu_{\tilde{I}}^{+}(x)$ and $v_{\tilde{I}}^{-}(x) \leq v_{\tilde{I}}^{+}(x)$

$\mu_{\tilde{I}}^{+}(x)+v_{\tilde{I}}^{+}(x) \leq 1$

Definition 3. Some basic arithmetical operations of two I VIF numbers $\quad\left(\tilde{\alpha}=\left[\begin{array}{c}\mu_{\alpha}^{-}, \mu_{\tilde{\alpha}}^{+}\end{array}\right],\left[\begin{array}{c}v_{\alpha}^{-}, v_{\tilde{\alpha}}^{+} \\ \tilde{\alpha}\end{array} \quad\right.\right.$ a n d $\tilde{\beta}=\left[\mu_{\tilde{\beta}}^{-}, \mu_{\tilde{\beta}}^{+}\right],\left[\begin{array}{c}v_{\tilde{\beta}}^{-}, v_{\tilde{\beta}}^{+} \\ \tilde{\beta}\end{array}\right]$ ) are given as following (Aydin and Seker 2020):

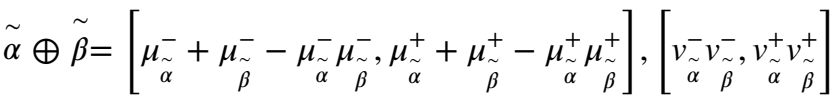

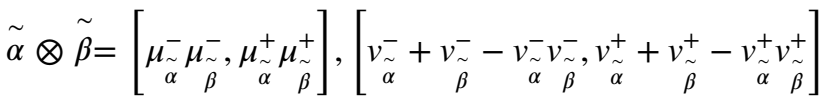

$\lambda \tilde{\alpha}=\left[1-\left(1-\mu_{\tilde{\alpha}}^{-}\right)^{\lambda}, 1-\left(1-\mu_{\tilde{\alpha}}^{+}\right)^{\lambda}\right],\left[\left(v_{\tilde{\alpha}}^{-}\right)^{\lambda},\left(\begin{array}{c}v_{\tilde{\alpha}}^{+} \\ { }^{\lambda}\end{array}\right]\right.$

$(\tilde{\alpha})^{\lambda}=\left[\left(\mu_{\tilde{\alpha}}^{-}\right)^{\lambda},\left(\mu_{\tilde{\alpha}}^{+}\right)^{\lambda}\right],\left[1-\left(1-v_{\tilde{\alpha}}^{-}\right)^{\lambda}, 1-\left(1-v_{\tilde{\alpha}}^{+}\right)^{\lambda}\right]$

Definition 5. An IVIF number $\tilde{\alpha}=\left[\mu_{\tilde{\alpha}}^{-}, \mu_{\tilde{\alpha}}^{+}\right],\left[v_{\tilde{\alpha}}^{-}, v_{\tilde{\alpha}}^{+}\right]$is defuzzified via (Aydin and Seker 2020):

$\mathcal{D}(\tilde{\alpha})=\frac{\mu_{\tilde{\alpha}}^{-}+\mu_{\tilde{\alpha}}^{+}+\left(1-v_{\tilde{\alpha}}^{-}\right)+\left(1-v_{\tilde{\alpha}}^{+}\right)+\mu_{\tilde{\alpha}}^{-} \mu_{\tilde{\alpha}}^{+}-\sqrt{\left(1-v_{\tilde{\alpha}}^{-}\right)\left(1-v_{\tilde{\alpha}}^{+}\right)}}{4}$

Based on the definitions and explanations above, the steps of the IVIF-AHP are given in the following:

Step 1: The pairwise comparison matrix is constructed by converting linguistic terms to IVIF numbers as given in Table 3 (Kahraman et al. 2020).
Table 3 Scale for the IVIF-AHP evaluations

\begin{tabular}{lllll}
\hline & \multicolumn{4}{l}{ IVIF number } \\
\cline { 2 - 5 } Linguistic terms & $\mu_{I}^{-}$ & $\mu_{I}^{+}$ & $v_{I}^{-}$ & $v_{I}^{+}$ \\
\hline Absolutely low importance (AL) & 0.1 & 0.25 & 0.65 & 0.75 \\
Very low importance (VL) & 0.15 & 0.3 & 0.6 & 0.7 \\
Low importance (L) & 0.2 & 0.35 & 0.55 & 0.65 \\
Medium low importance (ML) & 0.25 & 0.4 & 0.5 & 0.6 \\
Equal importance (EE) & 0.5 & 0.5 & 0.5 & 0.5 \\
Medium high importance (MH) & 0.5 & 0.6 & 0.25 & 0.4 \\
High importance (H) & 0.55 & 0.65 & 0.2 & 0.35 \\
Very high importance (VH) & 0.6 & 0.7 & 0.15 & 0.3 \\
Absolutely high importance (AH) & 0.65 & 0.75 & 0.1 & 0.25 \\
\hline
\end{tabular}

Step 2: The consistency of the matrix is analyzed using the crisp values proposed by Saaty (1977). Consistency ratio $(\mathrm{CR})$ is calculated using the matrix consistency index (CI) (Ayyildiz and Taskin Gumus 2021b):where $\lambda_{\max }$ is the maximum eigenvalue of the decision matrix and $n$ is the matrix order (Duleba and Moslem 2019). Then, CR is calculated (Solangi et al. 2019a):

$C R=\frac{C I}{R I}$

where RI is the Random Index and it depends on matrix order Saaty (1994).

$C I=\frac{\lambda_{\max }-n}{n-1}$

Step 3: Score of each element is determined.

$S(\tilde{I})=\frac{\mu_{\tilde{I}}^{-}(x)+\mu_{\tilde{I}}^{+}(x)-v_{\tilde{I}}^{-}(x)+v_{\tilde{I}}^{+}(x)}{2}$

Step 4: Interval exponential matrix is calculated.

$I=\left[\begin{array}{ccc}{\left[e^{\left(\mu_{s_{11}}^{-}-v_{s_{11}}^{+}\right)}, e^{\left(\mu_{s_{11}}^{+}-v_{s_{11}}^{-}\right)}\right]} & \cdots & {\left[e^{\left(\mu_{s_{1 n}}^{-}-v_{s_{1 n}}^{+}\right)}, e^{\left(\mu_{s_{1 n}}^{+}-v_{s_{1 n}}^{-}\right)}\right]} \\ \vdots & \ddots & \vdots \\ {\left[e^{\left(\mu_{s_{n 1}}^{-}-v_{s_{11}}^{+}\right)}, e^{\left(\mu_{s_{n 1}}^{+}-v_{s_{n 1}}^{-}\right)}\right]} & \cdots & {\left[e^{\left(\mu_{s_{n n}}^{-}-v_{s_{n n}}^{+}\right)}, e^{\left(\mu_{s_{n n}}^{+}-v_{s_{n n}}^{-}\right)}\right]}\end{array}\right]$
$\tilde{A}=\left[\begin{array}{ccc}{\left[\tilde{a}_{11}^{-}, \tilde{a}_{11}^{+}\right]} & \cdots & {\left[\tilde{a}_{1 n}^{-}, \tilde{a}_{1 n}^{+}\right]} \\ \vdots & \ddots & \vdots \\ {\left[\tilde{a}_{n 1}^{-}, \tilde{a}_{n 1}^{+}\right]} & \cdots & {\left[\tilde{a}_{n n}^{-}, \tilde{a}_{n n}^{+}\right]}\end{array}\right]$

Step 5: Priority vector is calculated for each criterion. 


$$
\tilde{W}_{j}=\left[w_{j}^{+}, w_{j}^{-}\right]=\left[\frac{\sum_{i=1}^{n} \tilde{a}_{i j}^{-}}{\sum_{i=1}^{n} \sum_{j=1}^{n} \tilde{a}_{i j}^{+}}, \frac{\sum_{i=1}^{n} \tilde{a}_{i j}^{+}}{\sum_{i=1}^{n} \sum_{j=1}^{n} \tilde{a}_{i j}^{-}}\right]
$$

Step 6: The possibility degree matrix is constructed.

$$
p_{i j}=\frac{\max \left(0, w_{j}^{+}-w_{i}^{-}\right)-\max \left(0, w_{j}^{-}-w_{i}^{+}\right)}{\left(w_{i}^{+}-w_{i}^{-}\right)+\left(w_{j}^{+}-w_{j}^{-}\right)}
$$

Step 7: The unnormalized weights are calculated.

$$
w_{j}=\frac{\sum_{i=1}^{n}-1+p_{i j}}{n}+0.5
$$

Step 8: The weights are normalized.

$$
w_{j}^{T}=\frac{w_{j}}{\sum_{i=1}^{n} w_{j}}
$$

\section{The weight determination}

To determine the importance weight of each performance attribute, an expert group is formed based on their experience. Company managers, academicians, and logistics firms' managers are included in the expert group to evaluate performance attributes from different perspectives. Seven experts from different expertness, three academicians working in supply chain, two managers from different companies, and one expert from transportation sector are consulted to take their opinions. The Modified Delphi Method is utilized to consolidate expert opinions in decision-making process. The method accumulates the opinions of anonymous experts on a particular topic (Gumus 2009). Experts share their knowledge, expertise, and opinions until a consensus is achieved (Ayyildiz et al. 2020). The method can summarize expert opinions up to 30 experts (Chang et al. 2008). The steps of Modified Delphi are given in Fig. 3.

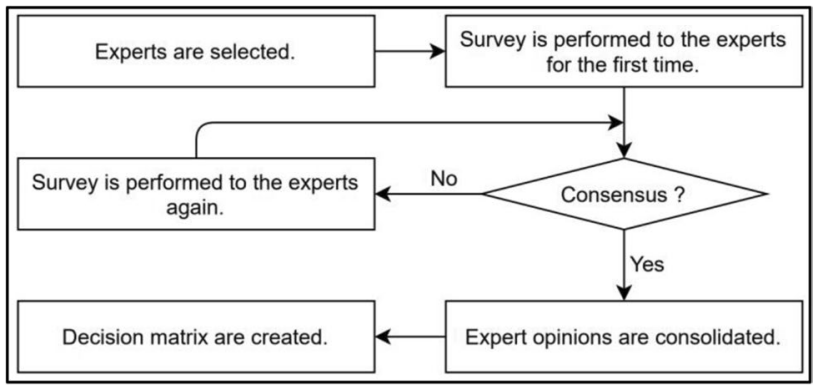

Fig. 3 The Modified Delphi's steps
The goal of Modified Delphi method is to reach a consensus on a particular subject by group thinking. To achieve a consensus, seven experts are consulted in this study. That is, the process progressed until a single group decision was obtained. Experts' weights are assumed as equal.

\section{Determination of the weights of level 1 performance attributes by BWM}

First, level 1 performance attributes are evaluated by experts. Experts determined PA-6: Organizational as the most important (the best) level 1 performance attribute and PA-5: Assets as the least important (the worst) level 1 performance attribute according to the Modified Delphi. Then, both the pairwise comparison between the bests with the other level 1 performance attributes and the pairwise comparison between the others with the worst are performed. The pairwise comparisons are given in Table 4.

The importance weights of level 1 performance attributes are determined based on Table 4 via the mathematical model explained in step 5 of the BWM. The weights of level 1 performance attributes are given in Table 5.

The $\zeta$ value is determined as 0.057 . To check the consistency of the proposed model, the consistency ratio is calculated (Moslem et al. 2020).

Consistency ratio $=\frac{\zeta}{\text { Consistency index }}$

The consistency index value is determined based on Table 6 (Rezaei 2015; Omrani et al. 2020). If the consistency ratio is lower than 1 , the matrix is determined as acceptable (Moslem et al. 2020).

The consistency ratio is determined as $0.015(0.057 / 3.73)$ in this study. So the results are determined as consistent.

Table 4 Pairwise comparisons for level 1 performance attributes

\begin{tabular}{llll}
\hline Best & Worst & $\boldsymbol{A}_{\boldsymbol{B}}$ & $\boldsymbol{A}_{\boldsymbol{w}}^{\boldsymbol{T}}$ \\
\hline Organizational & Assets & $(3,2,3,4,5,1,2)$ & $(3,3,2,2,1,4,4)$ \\
\hline
\end{tabular}

Table 5 The weights of level 1 performance attributes

\begin{tabular}{ll}
\hline Level 1 performance Attribute & Weight \\
\hline PA-1: Reliability & 0.114 \\
PA-2: Flexibility & 0.171 \\
PA-3: Responsiveness & 0.114 \\
PA-4: Cost & 0.086 \\
PA-5: Assets & 0.058 \\
PA-6: Organizational & 0.286 \\
PA-7: Environmental & 0.171 \\
\hline
\end{tabular}


Table 6 The consistency index values

Table 7 Pairwise comparison matrices for PA-1: Reliability and PA-2: Flexibility

\begin{tabular}{llllllllll}
\hline $\boldsymbol{a}_{\boldsymbol{B} \boldsymbol{w}}$ & $\mathbf{1}$ & 2 & 3 & $\mathbf{4}$ & $\mathbf{5}$ & $\mathbf{6}$ & $\mathbf{7}$ & $\mathbf{8}$ & $\mathbf{9}$ \\
\hline Consistency Index & 0.00 & 0.44 & 1.00 & 1.63 & 2.3 & 3.00 & 3.73 & 4.47 & 5.23 \\
\hline
\end{tabular}

\begin{tabular}{llllllll}
\hline Reliability & 1.1 & 1.2 & 1.3 & Flexibility & 2.1 & 2.2 & 2.3 \\
\hline 1.1 Quality & EE & ML & MH & 2.1 Production & EE & VH & MH \\
1.2 Accuracy & MH & EE & H & 2.2 Delivery & VL & EE & L \\
1.3 Perception & ML & L & EE & 2.3 Risk & ML & H & EE \\
\hline
\end{tabular}

Table 8 Pairwise comparison matrices for PA-3:

Responsiveness, PA-4: Cost, and PA-5: Assets

\begin{tabular}{lllllllll}
\hline Responsiveness & 3.1 & 3.2 & Cost & 4.1 & 4.2 & Assets & 5.1 & 5.2 \\
\hline 3.1 Operations & EE & MH & 4.1 Financial & EE & H & 5.1 Internal & EE & EE \\
3.2 Supplier & ML & EE & 4.2 Managerial & L & EE & 5.2 External & EE & EE \\
\hline
\end{tabular}

Table 9 Pairwise comparison matrices for PA-6: Organizational and PA-7: Environmental

\begin{tabular}{llllllllll}
\hline Organizational & 6.1 & 6.2 & 6.3 & 6.4 & Environmental & 7.1 & 7.2 & 7.3 & 7.4 \\
\hline 6.1 Cooperation & EE & MH & H & AH & 7.1 Consumption & EE & MH & H & H \\
6.2 Preparedness & ML & EE & MH & H & 7.2 Waste & ML & EE & H & MH \\
6.3 Supply chain based & L & ML & EE & MH & 7.3 Competency & L & L & EE & ML \\
6.4 Social & AL & L & ML & EE & 7.4 Supply chain design & L & ML & MH & EE \\
\hline
\end{tabular}

As can be seen from Table 5, the most important level 1 performance attribute for SCOR-embedded green supply chain resilience model is found as PA-6: Organizational with 0.286 . This attribute is followed by PA-2: Flexibility and PA-7: Environmental both with the weight of 0.171 . The least important performance attribute in this study is determined as the PA-5: Assets as expected with 0.058 among seven different level 1 performance attributes.

\section{Determination of the weights of inner levels by IVIF-AHP}

Level 2 and Level 3 performance attributes are evaluated by the same expert. Again, Modified Delphi method is utilized to consolidate experts' opinions. Pairwise comparison matrices are constructed with linguistic terms given in Table 3. Firstly, pairwise comparison matrices of level 2 performance attributes are constructed for each level 1 performance attributes. Tables 7, 8 , and 9 present the pairwise comparisons of inner level 2 performance attributes for each level 1 performance attribute.

The matrices are analyzed for consistency. Inconsistent matrices are reevaluated by experts and they are reconstructed to be consistent. Table 10 shows consistency ratios for level 2 pairwise comparison matrices. The consistency ratios for PA-3: Responsiveness, PA-4: Cost, and PA-5:
Table 10 Consistency ratios of level 2 pairwise comparison matrices

\begin{tabular}{ll}
\hline Matrix & $\begin{array}{l}\text { Consist- } \\
\text { ency } \\
\text { Ratio }\end{array}$ \\
\hline PA-1: Reliability & 0.040 \\
PA-2: Flexibility & 0.068 \\
PA-6: Organizational & 0.028 \\
PA-7: Environmental & 0.073 \\
\hline
\end{tabular}

Assets cannot be calculated because when the matrix order is 2 , the RI is zero and these matrices must be consistent (Dodd et al. 1993).

After the matrices are determined as consistent, weights of level 2 performance attributes are calculated using IVIFAHP. To determine the final weight of level 2 performance attributes, the determined weight by IVIF-AHP is multiplied by the corresponding level 1 performance attribute weight determined by the BWM. Table 11 presents the local and final weights of level 2 performance attributes.

As can be seen from Table 11, the most important level 2 performance attribute for SCOR-embedded green supply chain resilience model is determined as PA-6.1: Cooperation with 0.1 . This means that cooperation between all supply chain stakeholders plays a key role to make more resilient supply chains. 
Table 11 The weights of the level 2 performance attributes

\begin{tabular}{llllll}
\hline Performance attribute & Local weight & Final weight & Performance attribute & Local weight & Final weight \\
\hline PA-1.1: Quality & 0.339 & 0.039 & PA-5.1: Internal & 0.500 & 0.029 \\
PA-1.2: Accuracy & 0.460 & 0.053 & PA-5.2: External & 0.500 & 0.029 \\
PA-1.3: Perception & 0.201 & 0.023 & PA-6.1: Cooperation & 0.349 & 0.100 \\
PA-2.1: Production & 0.459 & 0.079 & PA-6.2: Preparedness & 0.290 & 0.219 \\
PA-2.2: Delivery & 0.176 & 0.030 & PA-6.3: Supply chain Based & 0.142 & 0.083 \\
PA-2.3: Risk & 0.366 & 0.063 & PA-6.4: Social & 0.337 & 0.040 \\
PA-3.1: Operations & 0.724 & 0.083 & PA-7.1: Consumption & 0.290 & 0.058 \\
PA-3.2: Supplier & 0.276 & 0.032 & PA-7.2: Waste & 0.156 & 0.050 \\
PA-4.1: Financial & 0.750 & 0.064 & PA-7.3: Competency & 0.027 \\
PA-4.2: Managerial & 0.250 & 0.021 & PA-7.4: Supply chain Design & 0.218 & 0.037 \\
\hline
\end{tabular}

Table 12 Pairwise comparison for PA-1.2: Accuracy

\begin{tabular}{lllll}
\hline PA-1.2: Accuracy & 1.2 .1 & 1.2 .2 & 1.2 .3 & 1.2 .4 \\
\hline 1.2.1 Scrap quality & $\mathrm{EE}$ & $\mathrm{VL}$ & $\mathrm{ML}$ & $\mathrm{EE}$ \\
1.2.2 Defective rate & $\mathrm{VH}$ & $\mathrm{EE}$ & $\mathrm{MH}$ & $\mathrm{MH}$ \\
1.2.3 Delivery performance & $\mathrm{MH}$ & $\mathrm{ML}$ & $\mathrm{EE}$ & $\mathrm{MH}$ \\
1.2.4 Turnover & $\mathrm{EE}$ & $\mathrm{ML}$ & $\mathrm{ML}$ & $\mathrm{EE}$ \\
\hline
\end{tabular}

This attribute is followed by the PA-6.2: Preparedness and PA-3.1: Operations both with the weight of 0.083 . The least important level 2 performance attribute in this study is determined as the PA-4.2: Managerial (Cost) with the 0.021 among twenty level 2 performance attributes.

Pairwise comparison matrices of level 3 performance attributes are constructed for each level 2 performance attribute. Table 12 presents the pairwise comparisons of inner level 3 performance attribute for PA-1.2: Accuracy level 2 performance attribute as an example.

Then, the matrices are analyzed for consistency. Table 13 shows consistency ratios for level 3 pairwise comparison matrices.

The consistency ratios for the some matrices are left blank in Table 13, because their matrix order is 2 . As can be seen in Table 13, all matrices are determined as consistent. Again, IVIF-AHP is applied to determine weights. To determine the final weight of level 3 performance attributes, the determined weight by IVIF-AHP is multiplied by the corresponding level 2 weight. Table 14 presents final weights of level 3 performance attributes.

If the level 3 performance attributes are focused on, PA-6.1.1: System Integration is the most important level 3 performance attribute with the highest importance rate of $4.6 \%$. It can be said that integrated systems have more impact on the green supply chain resilience than other level 3 performance attributes. Then, PA-3.1.1: Operating Capacity, PA-6.1.2: Collaboration, and PA-2.3.3: Risk Reduction must be taken into consideration to develop more resilient strategies, with importance rates of 3.8\%, 3.4\%, and 3.1\% respectively. Also, the least important sub-risk factors are obtained as PA-5.1.3: Strategic Stock and PA-4.2.2: Ethical Pricing with importance rates less than 5\%.

In the case of PA-1: Reliability, PA-1.2.2: Defective Rate and PA-1.3.1: Trust are determined as the most important level 3 performance attributes. Their weights are very close to each other. So, supply chains should produce their output with minimum defective rate, and aim to increase their trust to make more resilient supply chains, especially during hard
Table 13 Consistency ratios of level 3 pairwise comparison matrices

\begin{tabular}{llll}
\hline Matrix & Consistency ratio & Matrix & Consistency ratio \\
\hline PA-1.1: Quality & 0.068 & PA-5.1: Internal & 0.043 \\
PA-1.2: Accuracy & 0.046 & PA-5.2: External & 0 \\
PA-1.3: Perception & - & PA-6.1: Cooperation & 0.04 \\
PA-2.1: Production & 0.043 & PA-6.2: Preparedness & 0 \\
PA-2.2: Delivery & - & PA-6.3: Supply chain based & 0.073 \\
PA-2.3: Risk & 0 & PA-6.4: Social & 0.068 \\
PA-3.1: Operations & 0.04 & PA-7.1: Consumption & 0.04 \\
PA-3.2: Supplier & - & PA-7.2: Waste & 0.068 \\
PA-4.1: Financial & 0.073 & PA-7.3: Competency & 0 \\
PA-4.2: Managerial & 0.04 & PA-7.4: Supply chain design & 0.068 \\
\hline
\end{tabular}


Table 14 The final weights and ranks for all level 3 performance attributes

\begin{tabular}{|c|c|c|c|c|c|}
\hline Performance attribute & Weight & Rank & Performance attribute & Weight & Rank \\
\hline 1.1.1 Quality assurance & 0.008 & 52 & 5.1.1 Process automation & 0.006 & 60 \\
\hline 1.1.2 Service quality & 0.012 & 38 & 5.1.2 Technology level & 0.010 & 46 \\
\hline 1.1.3 Product quality & 0.019 & 20 & 5.1.3 Strategic stock & 0.004 & 62 \\
\hline 1.2.1 Scrap quality & 0.009 & 48 & 5.1.4 Emergency order & 0.008 & 49 \\
\hline 1.2.2 Defective rate & 0.018 & 21 & 5.2.1 Redundant supplier & 0.007 & 56 \\
\hline 1.2.3 Delivery performance & 0.015 & 30 & 5.2.2 Outsourcing & 0.007 & 56 \\
\hline 1.2.4 Turnover & 0.010 & 43 & 5.2.3 Multiple sourcing & 0.014 & 32 \\
\hline 1.3.1 Trust & 0.017 & 24 & 6.1.1 System integration & 0.046 & 1 \\
\hline 1.3.2 Overall reputation & 0.006 & 61 & 6.1.2 Collaboration & 0.034 & 3 \\
\hline 2.1.1 Flexible manufacturing System & 0.023 & 12 & 6.1.3 Information sharing & 0.020 & 16 \\
\hline 2.1.2 Production mix Flexibility & 0.017 & 25 & 6.2.1 Disaster planning & 0.028 & 6 \\
\hline 2.1.3 Adaptive capability & 0.012 & 39 & 6.2.2 Pandemic planning & 0.028 & 6 \\
\hline 2.1.4 Capacity flexibility & 0.027 & 8 & 6.2.3 Strategic fit & 0.014 & 33 \\
\hline 2.2.1 Contract flexibility & 0.008 & 53 & 6.2.4 Forecast accuracy & 0.014 & 33 \\
\hline 2.2.2 Time flexibility & 0.023 & 13 & 6.3.1 Leanness & 0.010 & 47 \\
\hline 2.3.1 Risk oversight & 0.016 & 27 & 6.3.2 Visibility & 0.013 & 35 \\
\hline 2.3.2 Risk management & 0.031 & 4 & 6.3.3 Supply chain knowledge & 0.021 & 15 \\
\hline 2.3.3 Risk reduction & 0.016 & 27 & 6.3.4 Supply chain complexity & 0.019 & 19 \\
\hline 3.1.1 Operating capacity & 0.038 & 2 & 6.4.1 Political support & 0.020 & 18 \\
\hline 3.1.2 Operating time & 0.028 & 5 & 6.4.2 Training and education & 0.013 & 37 \\
\hline 3.1.3 Operation agility & 0.017 & 26 & 6.4.3 Social responsibility & 0.008 & 50 \\
\hline 3.2.1 Lead time & 0.024 & 11 & 7.1.1 Energy consumption & 0.027 & 9 \\
\hline 3.2.2 Location & 0.008 & 51 & 7.1.2 Raw material Consumption & 0.020 & 17 \\
\hline 4.1.1 Purchasing cost & 0.010 & 42 & 7.1.3.Recycling material & 0.012 & 41 \\
\hline 4.1.2 Product(ion) cost & 0.021 & 14 & 7.2.1 Waste management & 0.024 & 10 \\
\hline 4.1.3 Operational cost & 0.015 & 31 & 7.2.2 Pollution production & 0.016 & 29 \\
\hline 4.1.4 Transportation cost & 0.018 & 23 & 7.2.3 Hazardous material & 0.010 & 44 \\
\hline 4.2.1 Cost optimization & 0.007 & 55 & 7.3.1 Environmental Management Sys & 0.013 & 36 \\
\hline 4.2.2 Ethical pricing & 0.004 & 63 & 7.3.2 Safety competencies & 0.007 & 58 \\
\hline \multirow[t]{4}{*}{ 4.2.3 Financial stability } & 0.010 & 45 & 7.3.3 Environmental certificate & 0.007 & 58 \\
\hline & & & 7.4.1 Environmental design & 0.018 & 22 \\
\hline & & & 7.4.2 Land usage & 0.007 & 54 \\
\hline & & & 7.4.3 Reverse logistics & 0.012 & 40 \\
\hline
\end{tabular}

times such as pandemic and disaster. PA-2.3.2: Risk Management is the most important level 3 attribute for PA-2: Flexibility. More systematic and comprehensive risk management enables to increase the resilience of green supply chains. Operating time and capacity are important factors to give quick response for sudden changes. Production, operational, and transportation costs should be reduced as much as possible because disasters and pandemics often result in large demands. Importance weights of all level 3 performance attributes of PA-1: Assets are below average except PA-5.2.3: Multiple Sourcing. PA-7.1.1: Energy Consumption and PA-7.2.1: Waste Management are the most important performance attributes that consider the environmental impact of green supply chain.

\section{Practical implications}

In terms of practical implications, this study presents a comprehensive set of criteria to evaluate green supply chain resilience. A useful source of information is provided to supply chain practitioners and managers who seek to implement strategies to improve resilience of chain within and between organizations. This framework would eventually lead to supply chain resilience measurement tool for supply chain practitioners and managers, which would assist to improve their success in very competitive market. Additionally, methodological framework is provided to practitioners and managers to assess and improve their resilience performance. Organizational and environmental factors are identified essential precursors to the implementation of green and resilience 
strategies of supply chains. The fact that green supply chains act together by making more organized decisions and that all the stakeholders of the chain are included in the decision processes are effective in increasing the durability of both the individual and the whole chain. More integrated systems can enable all the stakeholders of the supply chains to share information and products faster and more effectively, enabling them to be more prepared for unexpected situations. Cooperation between stakeholders also plays an important role in increasing the resilience of both the stakeholders and the entire chain. In addition, according to the opinions of the experts consulted, making preliminary preparations for challenging unexpected situations such as disasters and pandemics is one of the lessons that the COVID-19 pandemic teaches supply chains.

Increasing operational capacity would enable supply chains to respond more quickly to increased demands in crisis situations, such as the COVID-19 pandemic. Thus, more resilient green supply chains can be built against changes in demand. Keeping the operation times as low as possible will ensure that the demands are met more effectively in limited times. Green supply chain managers should aim to reduce lead times, which are often defined as non-value adding activity. Additionally, this study proposes numerous areas which academician researchers could complete additional study and develop their future research agendas.

\section{Conclusion}

In globalizing world, green supply chains become more important than before. In this context, efficient supply chain management is required to maintain the profitability and continuity of the supply chains. Besides, the supply chain managers should consider environmental impacts and resilience of supply chain to construct a more robust supply chains when they decide about supply chain management. While the issues considered most critical to green supply chains are environmental sensitivity, efficiency, and cost control, the COVID-19 pandemic has highlighted the importance of resilience. Supply chains have experienced and continue to experience shocks and strains like never before with the COVID-19 pandemic. COVID-19 continues to have devastating effects on all supply chains globally. The chains that supply the raw materials and intermediate products they use in their products from the Far East feel these effects very intensely. On the other hand, COVID-19 is seriously changing the demand for products and services in all markets. The most important difference between the disruptions caused by the pandemic and the disruptions caused by other crises is that they are large, fast, and disruptive along all supply chains in terms of supply and demand. In addition to these changes observed in the short term, it is also necessary to evaluate the expected changes in both demand and supply in the medium and long term. Some of the important warnings that COVID-19 has given to green supply chains worldwide are the need to manage supply risks correctly and construct more resilient supply chain structures. Therefore, resilience of green supply chains should be evaluated more carefully and comprehensively.

The SCOR model that provides a standard methodology for managing supply chains can be used to evaluate organizational performance. The SCOR-embedded green supply chain resilience evaluation model is used in this study, as it successfully measures process performance and defines the supply chain in all its aspects, allowing for a comprehensive measurement and evaluation. Additionally, the SCOR model is extended with novel performance attributes to make a more comprehensive evaluation.

In this study, the green supply chain resilience evaluation is taken into consideration in post COVID-19 era. Firstly, the resilience evaluation model is constructed as a threelevel hierarchical performance attribute structure to present the SCOR-embedded resilience evaluation model. Then, a hybrid BWM-integrated IVIF-AHP methodology is proposed to determine the weights of each performance attribute in hierarchical structure. Experts are consulted to evaluate the performance attributes. The main contributions of this study are as follows: (1) SCOR model is adapted to resilience evaluation of green supply chain in COVID-19 era by adding new performance attributes; (2) the most significant performance attributes on the green supply chain resilience are determined and classified in hierarchical structure; (3) an expert group which consists of seven experts is formed to take their opinions about performance attribute, and expert opinions are consolidated via Modified Delphi method; (4) level 1 performance attributes are weighted by the BWM, their inner levels are weighted by the IVIF-AHP, and so the weight of each performance attribute is determined; (5) it is aimed that the proposed green supply chain resilience model and weighting method will be used by both public and private supply chains to improve their resilience strategies.

SCOR-embedded green supply chain resilience evaluation model can be used in different studies with different MCDM methodologies or heuristics. This model can be easily used in the supplier selection problem by using different performance attributes if necessary. The proposed method can also be applied in the evaluation of traditional supply chain resilience. The MCDM method presented in this study provides thoughtfulness, flexibility, and efficiency for decision-makers to use their subjectivity and preferences directly. The performance attributes used may differ according to the characteristics of the supply chains. Each supply chain can use this method by determining performance attributes suitable for its own characteristics while 
evaluating their resilience. Besides, different supply chains can be compared using this study.

Author contribution Ertugrul Ayyildiz contributes solely to the completion of the paper.

Availability of data and material Not applicable.

Code availability Not applicable.

\section{Declarations}

Ethical approval. Ethics committee approval is not required.

Consent to participate Not applicable.

Consent to publish The author confirms that the final version of the manuscript has been reviewed, approved, and consented for publication.

Conflict of interest The author declares no competing interest.

\section{References}

Ahi P, Searcy C (2013) A comparative literature analysis of definitions for green and sustainable supply chain management. J Clean Prod 52:329-341. https://doi.org/10.1016/J.JCLEPRO.2013.02.018

Al-Haidous S, Al-Ansari T (2020) Sustainable liquefied natural gas supply chain management: a review of quantitative models. Sustain 12:243

Alnaggar M, Bhanot N (2018) A machine learning approach for the identification of the Lattice Discrete Particle Model parameters. Eng Fract Mech 197:160-175. https://doi.org/10.1016/j.engfr acmech.2018.04.041

Arabsheybani A, Arshadi Khasmeh A (2021) Robust and resilient supply chain network design considering risks in food industry: flavour industry in Iran. Int J Manag Sci Eng Manag 1-12:1907811. https://doi.org/10.1080/17509653.2021.1907811

Aydin N, Seker S (2020) WASPAS based MULTIMOORA method under IVIF environment for the selection of hub location. $\mathrm{J}$ Enterp Inf Manag 33:1233-1256. https://doi.org/10.1108/ JEIM-09-2019-0277

Ayyildiz E, Taskin Gumus A (2021a) A novel distance learning ergonomics checklist and risk evaluation methodology: a case of Covid-19 pandemic. Hum Factors Ergon Manuf 31:397-411. https://doi.org/10.1002/hfm.20908

Ayyildiz E, Taskin Gumus A (2021b) Interval-valued Pythagorean fuzzy AHP method-based supply chain performance evaluation by a new extension of SCOR model: SCOR 4.0. Complex Intell Syst 7:559-576. https://doi.org/10.1007/s40747-020-00221-9

Ayyildiz E, Taskin Gumus A, Erkan M (2020) Individual credit ranking by an integrated interval type- 2 trapezoidal fuzzy Electre methodology. Soft Comput 24:16149-16163. https://doi.org/ 10.1007/s00500-020-04929-1

Baghizadeh K, Zimon D, Juma L (2021) Modeling and optimization sustainable forest supply chain considering discount in transportation system and supplier selection under uncertainty. Forests 12:964. https://doi.org/10.3390/F12080964

Bali O, Dagdeviren M, Gumus S (2015) An integrated dynamic intuitionistic fuzzy MADM approach for personnel promotion problem. Kybernetes 44:1422-1436. https://doi.org/10. 1108/K-07-2014-0142

Bansal T (2010) Primer: business sustainability. https://www.nbs.net/ articles/primer-business-sustainability. Accessed 2 Oct 2021

Barbieri P, Boffelli A, Elia S et al (2020) (2020) What can we learn about reshoring after Covid-19? Oper Manag Res 133(13):131136. https://doi.org/10.1007/S12063-020-00160-1

Beheshti HM, Oghazi P, Mostaghel R, Hultman M (2014) Supply chain integration and firm performance: an empirical study of Swedish manufacturing firms. Compet Rev 24:20-31. https:// doi.org/10.1108/CR-06-2013-0060

Bernardes ES, Hanna MD (2009) A theoretical review of flexibility, agility and responsiveness in the operations management literature: toward a conceptual definition of customer responsiveness. Int J Oper Prod Manag 29:30-53. https://doi.org/10. 1108/01443570910925352

Beskese A, Kahraman C, Ender Buyukbay S, Bozbura FT (2018) An intuitionistic fuzzy multi-expert and multi-criteria system for effective performance management. Technol Econ Dev Econ 24:2179-2201. https://doi.org/10.3846/tede.2018.6462

Büyüközkan G, Güleryüz S (2016) A new integrated intuitionistic fuzzy group decision making approach for product development partner selection. Comput Ind Eng 102:383-395. https:// doi.org/10.1016/j.cie.2016.05.038

Büyüközkan G, Göçer F, Karabulut Y (2019) A new group decision making approach with IF AHP and IF VIKOR for selecting hazardous waste carriers. Meas J Int Meas Confed 134:66-82. https://doi.org/10.1016/j.measurement.2018.10.041

Büyüközkan G, Havle CA, Feyzioğlu O (2020) A new digital service quality model and its strategic analysis in aviation industry using interval-valued intuitionistic fuzzy AHP. J Air Transp Manag 86:101817. https://doi.org/10.1016/j.jairtraman.2020. 101817

Cebi S, Ilbahar E (2018) Warehouse risk assessment using interval valued intuitionistic fuzzy AHP. Int J Anal Hierarchy Process 10:243-253. https://doi.org/10.13033/ijahp.v10i2.549

Chang CW, Wu CR, Chen HC (2008) Using expert technology to select unstable slicing machine to control wafer slicing quality via fuzzy AHP. Expert Syst Appl 34:2210-2220. https://doi.org/ 10.1016/j.eswa.2007.02.042

Chen D, Faibil D, Agyemang M (2020) Evaluating critical barriers and pathways to implementation of e-waste formalization management systems in Ghana: a hybrid BWM and fuzzy TOPSIS approach. Environ Sci Pollut Res 27:44561-44584. https://doi. org/10.1007/s11356-020-10360-8

Das D, Datta A, Kumar P et al (2021) Building supply chain resilience in the era of COVID-19: an AHP-DEMATEL approach. Oper Manag Res. https://doi.org/10.1007/s12063-021-00200-4

Das K, McClung W (2020) Green and resilient supply chain design model. In: Proceedings of the 2020 IISE Annual Conference. Institute of Industrial and Systems Engineers, IISE, pp 61-66

Dodd FJ, Donegan HA, McMaster TBM (1993) A statistical approach to consistency in AHP. Math Comput Model 18:19-22. https:// doi.org/10.1016/0895-7177(93)90123-G

Dogan O, Deveci M, Canitez F, Kahraman C (2019) A corridor selection for locating autonomous vehicles using an interval-valued intuitionistic fuzzy AHP and TOPSIS method. Soft Comput. https://doi.org/10.1007/s00500-019-04421-5

Duleba S, Moslem S (2019) Examining Pareto optimality in analytic hierarchy process on real Data: an application in public transport service development. Expert Syst Appl 116:21-30. https://doi. org/10.1016/j.eswa.2018.08.049

Ecer F (2021) Sustainability assessment of existing onshore wind plants in the context of triple bottom line: a best-worst method (BWM) based MCDM framework. Environ Sci Pollut Res 28:19677-19693. https://doi.org/10.1007/s11356-020-11940-4 
Elzarka S (2020) A study on using lean, agile, resilient and green index to assess the sustainability of Egyptian FMCGs supply chains. Int J Logist Syst Manag 37:173-224. https://doi.org/10.1504/ IJLSM.2020.110580

Fahimnia B, Jabbarzadeh A, Sarkis J (2018) Greening versus resilience: a supply chain design perspective. Transp Res Part E Logist Transp Rev 119:129-148. https://doi.org/10.1016/j.tre. 2018.09.005

Fallahpour A, Nayeri S, Sheikhalishahi M et al (2021) A hyper-hybrid fuzzy decision-making framework for the sustainable-resilient supplier selection problem: a case study of Malaysian Palm oil industry. Environ Sci Pollut Res. https://doi.org/10.1007/ s11356-021-12491-y

Foroozesh N, Tavakkoli-Moghaddam R, Mousavi SM, Vahdani B (2019) A new comprehensive possibilistic group decision approach for resilient supplier selection with mean-varianceskewness-kurtosis and asymmetric information under intervalvalued fuzzy uncertainty. Neural Comput Appl 31:6959-6979. https://doi.org/10.1007/s00521-018-3506-1

Fox MS, Barbuceanu M, Teigen R (2001) Agent-oriented supply-chain management. Information-Based Manuf 81-104.https://doi.org/ 10.1007/978-1-4615-1599-9_5

Ghomi-Avili M, Tavakkoli-Moghaddam R, Jalali Naeini SG, Jabbarzadeh A (2021) Competitive green supply chain network design model considering inventory decisions under uncertainty: a real case of a filter company. Int J Prod Res 59:4248-4267. https:// doi.org/10.1080/00207543.2020.1760391

Gumus AT (2009) Evaluation of hazardous waste transportation firms by using a two step fuzzy-AHP and TOPSIS methodology. Expert Syst Appl 36:4067-4074. https://doi.org/10.1016/j. eswa.2008.03.013

Haldar A, Ray A, Banerjee D, Ghosh S (2012) A hybrid MCDM model for resilient supplier selection. Int J Manag Sci Eng Manag 7:284-292. https://doi.org/10.1080/17509653.2012.10671234

Hinduja A, Pandey M (2018) Assessment of healthcare waste treatment alternatives using an integrated decision support framework. Int J Comput Intell Syst 12:318-333. https://doi.org/10.2991/ijcis. 2018.125905685

Hinduja A, Pandey M (2019) An integrated intuitionistic fuzzy MCDM approach to select cloud-based ERP system for SMEs. Int J Inf Technol Decis Mak 18:1875-1908. https://doi.org/10.1142/ S0219622019500378

Hosseini S, Al KA (2019) A hybrid ensemble and AHP approach for resilient supplier selection. J Intell Manuf 30:207-228. https:// doi.org/10.1007/s10845-016-1241-y

Huang CN, Liou JJH, Lo HW, Chang FJ (2021) Building an assessment model for measuring airport resilience. J Air Transp Manag 95:102101. https://doi.org/10.1016/J.JAIRTRAMAN.2021. 102101

Ikram M, Sroufe R, Zhang Q (2020a) Prioritizing and overcoming barriers to integrated management system (IMS) implementation using AHP and G-TOPSIS. J Clean Prod 254:120121. https://doi. org/10.1016/j.jclepro.2020.120121

Ikram M, Zhang Q, Sroufe R (2020b) Developing integrated management systems using an AHP-Fuzzy VIKOR approach. Bus Strateg Environ 29:2265-2283. https://doi.org/10.1002/bse.2501

Ji L, Yuan C, Feng T, Wang C (2020) Achieving the environmental profits of green supplier integration: the roles of supply chain resilience and knowledge combination. Sustain Dev 28:978989. https://doi.org/10.1002/sd.2050

Kahraman C, Öztayşi B, Çevik Onar S (2020) An integrated intuitionistic fuzzy AHP and TOPSIS approach to evaluation of outsource manufacturers. J Intell Syst 29:283-297. https://doi. org/10.1515/jisys-2017-0363

Karasan A (2019) A novel hesitant intuitionistic fuzzy linguistic AHP method and its application to prioritization of investment alternatives. Int J Anal Hierarchy Process 11:127-142. https:// doi.org/10.13033/ijahp.v11i1.610

Karasan A, Erdogan M, Ilbahar E (2018) Prioritization of production strategies of a manufacturing plant by using an integrated intuitionistic fuzzy AHP \& TOPSIS approach. J Enterp Inf Manag 31:510-528. https://doi.org/10.1108/JEIM-01-2018-0001

Karaşan A, Kaya İ, Erdoğan M (2020) Location selection of electric vehicles charging stations by using a fuzzy MCDM method: a case study in Turkey. Neural Comput Appl 32:4553-4574. https://doi.org/10.1007/s00521-018-3752-2

Khemiri R, Elbedoui-Maktouf K, Grabot B, Zouari B (2017) A fuzzy multi-criteria decision-making approach for managing performance and risk in integrated procurement-production planning. Int J Prod Res 55:5305-5329. https://doi.org/10.1080/00207 543.2017.1308575

Kheybari S, Kazemi M, Rezaei J (2019) Bioethanol facility location selection using best-worst method. Appl Energy 242:612-623. https://doi.org/10.1016/j.apenergy.2019.03.054

Li M, Zhang J (2021) Integrating Kano Model, AHP, and QFD methods for new product development based on text mining, intuitionistic fuzzy sets, and customers satisfaction. Math Probl Eng. https://doi.org/10.1155/2021/2349716

Lockamy A, Mccormack K (2004) The development of a supply chain management process maturity model using the concepts of business process orientation. Supply Chain Manag an Int J 9:272-278. https://doi.org/10.1108/13598540410550019

Luo Y, Chen X, Fang F et al (2021) A trust-enhanced and preferenceaware collaborative method for recommending new energy vehicle. Environ Sci Pollut Res 28:7901-7917. https://doi.org/ 10.1007/s11356-020-10834-9

Mahmoudi A, Javed SA, Mardani A (2021) Gresilient supplier selection through Fuzzy Ordinal Priority Approach: decision-making in post-COVID era. Oper Manag Res. https://doi.org/10. 1007/s12063-021-00178-z

Malek A, Ebrahimnejad S, Tavakkoli-Moghaddam R (2017) An improved hybrid grey relational analysis approach for green resilient supply chain network assessment. Sustain 9:1433. https://doi.org/10.3390/su9081433

Mari SI, Lee YH, Memon MS (2014) Sustainable and resilient supply chain network design under disruption risks. Sustain 6:6666-6686. https://doi.org/10.3390/su6106666

Mohammed A (2020) Towards 'gresilient' supply chain management: a quantitative study. Resour Conserv Recycl 155:104641. https://doi.org/10.1016/j.resconrec.2019.104641

Mohammed A, Yazdani M, Oukil A, Santibanez Gonzalez EDR (2021) A hybrid mcdm approach towards resilient sourcing. Sustain 13:1-31. https://doi.org/10.3390/su13052695

Moslem S, Campisi T, Szmelter-Jarosz A et al (2020) Best-worst method for modelling mobility choice after COVID-19: evidence from Italy. Sustain 12:6824. https://doi.org/10.3390/ SU12176824

Müller JM (2019) Contributions of Industry 4.0 to quality management - a SCOR perspective. IFAC-PapersOnLine 52:1236-1241. https://doi.org/10.1016/j.ifacol.2019.11.367

Murat Ar I, Erol I, Peker I et al (2020) Evaluating the feasibility of blockchain in logistics operations: a decision framework. Expert Syst Appl 158:113543. https://doi.org/10.1016/j.eswa.2020. 113543

Namdar J, Torabi SA, Sahebjamnia N, Nilkanth Pradhan N (2021) Business continuity-inspired resilient supply chain network design. Int J Prod Res 59:1331-1367. https://doi.org/10.1080/ 00207543.2020 .1798033

Negri M, Cagno E, Colicchia C, Sarkis J (2021) Integrating sustainability and resilience in the supply chain: a systematic literature review and a research agenda. Bus Strateg Environ. https://doi. org/10.1002/bse.2776 
Nirmala G, Uthra G (2017) Quality of online shopping websites in India: a study using intuitionistic fuzzy AHP. J Adv Res Dyn Control Syst 9:117-124

Ntabe EN, LeBel L, Munson AD, Santa-Eulalia LA (2015) A systematic literature review of the supply chain operations reference (SCOR) model application with special attention to environmental issues. Int J Prod Econ 169:310-332

Omrani H, Alizadeh A, Amini M (2020) A new approach based on BWM and MULTIMOORA methods for calculating semi-human development index: an application for provinces of Iran. Socioecon Plann Sci 70:100689. https://doi.org/10.1016/j.seps.2019. 02.004

Otay İ, Oztaysi B, Cevik Onar S, Kahraman C (2017) Multi-expert performance evaluation of healthcare institutions using an integrated intuitionistic fuzzy AHP\&DEA methodology. Knowledge-Based Syst 133:90-106. https://doi.org/10.1016/j.knosys.2017.06.028

Ouyang X, Guo F (2018) Intuitionistic fuzzy analytical hierarchical processes for selecting the paradigms of mangroves in municipal wastewater treatment. Chemosphere 197:634-642. https://doi. org/10.1016/j.chemosphere.2017.12.102

Pamucar D, Yazdani M, Obradovic R et al (2020) A novel fuzzy hybrid neutrosophic decision-making approach for the resilient supplier selection problem. Int J Intell Syst 35:1934-1986. https://doi.org/ 10.1002/int.22279

Pramanik D, Haldar A, Mondal SC et al (2017) Resilient supplier selection using AHP-TOPSIS-QFD under a fuzzy environment. Int $\mathbf{J}$ Manag Sci Eng Manag 12:45-54. https://doi.org/10.1080/17509 653.2015.1101719

Pulansari F, Putri A (2020) Green Supply Chain Operation Reference (Green SCOR) performance evaluation (case study: steel company). In: Journal of Physics: Conference Series. IOP Publishing, p 32006

Rai PK, Kumar PNR, Sivakumar AI et al (2011) Impact of aggregating supplies from single supplier to a cluster of producers: opportunities for 3PL service providers. Int J Oper Res 12:192-206. https://doi.org/10.1504/IJOR.2011.042505

Rajesh R (2020) A grey-layered ANP based decision support model for analyzing strategies of resilience in electronic supply chains. Eng Appl Artif Intell 87:103338. https://doi.org/10.1016/j.engap pai.2019.103338

Rajesh R (2021) Optimal trade-offs in decision-making for sustainability and resilience in manufacturing supply chains. J Clean Prod 313:127596. https://doi.org/10.1016/j.jclepro.2021.127596

Rajesh R, Ravi V (2015) Supplier selection in resilient supply chains: a grey relational analysis approach. J Clean Prod 86:343-359. https://doi.org/10.1016/j.jclepro.2014.08.054

Ramirez-Peña M, Sánchez Sotano AJ, Pérez-Fernandez V et al (2020) Achieving a sustainable shipbuilding supply chain under I4.0 perspective. J Clean Prod 244:118789. https://doi.org/10.1016/J. JCLEPRO.2019.118789

Rauer J, Kaufmann L (2015) Mitigating external barriers to implementing green supply chain management: a grounded theory investigation of green-tech companies' rare earth metals supply chains. J Supply Chain Manag 51:65-88. https://doi.org/10.1111/ JSCM.12063

Rezaei J (2015) Best-worst multi-criteria decision-making method. Omega (United Kingdom) 53:49-57. https://doi.org/10.1016/j. omega.2014.11.009

Saaty TL (1977) A scaling method for priorities in hierarchical structures. J Math Psychol 15:234-281. https://doi.org/10.1016/00222496(77)90033-5

Saaty TL (1988) What is the analytic hierarchy process? Mathematical Models for Decision Support. Springer, Berlin Heidelberg, pp 109-121
Saaty TL (1994) How to make a decision: the analytic hierarchy process. Interfaces (providence) 24:19-43. https://doi.org/10.1287/ inte.24.6.19

Sabouhi F, Pishvaee MS, Jabalameli MS (2018) Resilient supply chain design under operational and disruption risks considering quantity discount: a case study of pharmaceutical supply chain. Comput Ind Eng 126:657-672. https://doi.org/10.1016/j.cie.2018.10. 001

Sachin N, Rajesh R (2021) An empirical study of supply chain sustainability with financial performances of Indian firms. Environ Dev Sustain. https://doi.org/10.1007/s10668-021-01717-1

Sadiq R, Tesfamariam S (2009) Environmental decision-making under uncertainty using intuitionistic fuzzy analytic hierarchy process (IF-AHP). Stoch Environ Res Risk Assess 23:75-91. https://doi. org/10.1007/s00477-007-0197-Z

Sarkis J (2003) A strategic decision framework for green supply chain management. J Clean Prod 11:397-409. https://doi.org/10.1016/ S0959-6526(02)00062-8

Seker S, Aydin N (2020) Sustainable public transportation system evaluation: a novel two-stage hybrid method based on IVIF-AHP and CODAS. Int J Fuzzy Syst 22:257-272. https://doi.org/10.1007/ s40815-019-00785-w

Sen DK, Datta S, Mahapatra SS (2016) A TODIM-based decision support framework for G-resilient supplier selection in fuzzy environment. Asia-Pacific J Oper Res 33:1650033. https://doi.org/10. 1142/S0217595916500330

Sen MK, Dutta S, Kabir G (2021) Development of flood resilience framework for housing infrastructure system: integration of bestworst method with evidence theory. J Clean Prod 290:125197. https://doi.org/10.1016/J.JCLEPRO.2020.125197

Shafiee M, Zare Mehrjerdi Y, Keshavarz M (2021) Integrating lean, resilient, and sustainable practices in supply chain network: mathematical modelling and the AUGMECON2 approach. Int J Syst Sci Oper Logist. https://doi.org/10.1080/23302674.2021. 1921878

Sharma M, Joshi S (2020) Digital supplier selection reinforcing supply chain quality management systems to enhance firm's performance. TQM J. https://doi.org/10.1108/TQM-07-2020-0160

Shekari F, Moaven Z, Mobasheri AA et al (2021) Proposing a model for religious tourism development: evidence from Iran. Int $\mathrm{J}$ Relig Tour Pilgr 9:4. https://doi.org/10.21427/d45k-tm75

Solangi YA, Shah SAA, Zameer H et al (2019a) Assessing the solar PV power project site selection in Pakistan: based on AHP-fuzzy VIKOR approach. Environ Sci Pollut Res 26:30286-30302. https://doi.org/10.1007/s11356-019-06172-0

Solangi YA, Tan Q, Mirjat NH et al (2019b) An integrated Delphi-AHP and fuzzy TOPSIS approach toward ranking and selection of renewable energy resources in Pakistan. Processes 7:118. https:// doi.org/10.3390/pr7020118

Sun J, Peng X, Xu Y et al (2017) VIKOR-GRA based intuitionistic fuzzy multi-attribute WEB service selection. Bol Tec Bull 55:982-996

Taherkhani N, Sepehri MM, Shafaghi S, Khatibi T (2019) Identification and weighting of kidney allocation criteria: a novel multiexpert fuzzy method. BMC Med Inform Decis Mak 19:182. https://doi.org/10.1186/s12911-019-0892-y

Tavana M, Zareinejad M, Di Caprio D, Kaviani MA (2016) An integrated intuitionistic fuzzy AHP and SWOT method for outsourcing reverse logistics. Appl Soft Comput J 40:544-557. https:// doi.org/10.1016/j.asoc.2015.12.005

Tavana M, Shaabani A, Santos-Arteaga FJ, Valaei N (2021) An integrated fuzzy sustainable supplier evaluation and selection framework for green supply chains in reverse logistics. Environ Sci Pollut Res. https://doi.org/10.1007/s11356-021-14302-w 
Tooranloo HS, Iranpour A (2017) Supplier selection and evaluation using interval-valued intuitionistic fuzzy AHP method. Int J Procure Manag 10:539-554. https://doi.org/10.1504/IJPM.2017. 086399

Tooranloo HS, Ayatollah AS, Iranpour A (2018) A model for supplier evaluation and selection based on integrated interval-valued intuitionistic fuzzy AHP-TOPSIS approach. Int J Math Oper Res 13:401-417. https://doi.org/10.1504/IJMOR.2018.094854

Torabi SA, Baghersad M, Mansouri SA (2015) Resilient supplier selection and order allocation under operational and disruption risks. Transp Res Part E Logist Transp Rev 79:22-48. https://doi.org/ 10.1016/j.tre.2015.03.005

Tramarico CL, Salomon VAP, Marins FAS (2017) Multi-criteria assessment of the benefits of a supply chain management training considering green issues. J Clean Prod 142:249-256. https:// doi.org/10.1016/j.jclepro.2016.05.112

Trivellas P, Malindretos G, Reklitis P (2020) Implications of green logistics management on sustainable business and supply chain performance: evidence from a survey in the greek agri-food sector. Sustain 12:1-29. https://doi.org/10.3390/su122410515

Tseng ML, Lim M, Wu KJ et al (2018) A novel approach for enhancing green supply chain management using converged interval-valued triangular fuzzy numbers-grey relation analysis. Resour Conserv Recycl 128:122-133. https://doi.org/10.1016/j.resconrec.2017. 01.007

Tukamuhabwa BR, Stevenson M, Busby J, Zorzini M (2015) Supply chain resilience: definition, review and theoretical foundations for further study. Int J Prod Res 53:5592-5623

V. Parkouhi S, S. Ghadikolaei A (2017) A resilience approach for supplier selection: using Fuzzy Analytic Network Process and grey VIKOR techniques. J Clean Prod 161:431-451. https://doi.org/ 10.1016/j.jclepro.2017.04.175

Verma R, Chandra S (2021) Interval-valued intuitionistic fuzzyanalytic hierarchy process for evaluating the impact of security attributes in Fog based Internet of Things paradigm. Comput Commun 175:35-46. https://doi.org/10.1016/J.COMCOM.2021. 04.019

Viswanadham N, Samvedi A (2013) Supplier selection based on supply chain ecosystem, performance and risk criteria. Int J Prod Res 51:6484-6498. https://doi.org/10.1080/00207543.2013.825056

Wang H, Qian G, Feng X (2011) An intuitionistic fuzzy AHP based on synthesis of eigenvectors and its application. Inf Technol J 10:1850-1866. https://doi.org/10.3923/itj.2011.1850.1866

Wang X, Herty M, Zhao L (2016) Contingent rerouting for enhancing supply chain resilience from supplier behavior perspective. Int Trans Oper Res 23:775-796. https://doi.org/10.1111/itor.12151

Wang TK, Zhang Q, Chong HY, Wang X (2017) Integrated supplier selection framework in a resilient construction supply chain: an approach via analytic hierarchy process (AHP) and grey relational analysis (GRA). Sustain 9:289. https://doi.org/10.3390/ su9020289

Wu J, Huang H-B, Cao Q-W (2013) Research on AHP with intervalvalued intuitionistic fuzzy sets and its application in multi-criteria decision making problems. Appl Math Model 37:9898-9906. https://doi.org/10.1016/j.apm.2013.05.035

Xiong L, Zhong S, Liu S et al (2020) An approach for resilient-green supplier selection based on WASPAS, BWM, and TOPSIS under intuitionistic fuzzy sets. Math Probl Eng. https://doi.org/10.1155/ 2020/1761893

Xu Z, Liao H (2014) Intuitionistic fuzzy analytic hierarchy process. IEEE Trans Fuzzy Syst 22:749-761. https://doi.org/10.1109/ TFUZZ.2013.2272585

Yu W, Chavez R, Feng M, Wiengarten F (2014) Integrated green supply chain management and operational performance. Supply Chain Manag an Int J 19:683-696. https://doi.org/10.1108/ SCM-07-2013-0225

Yu X, Zheng D, Zhou L (2021) Credit risk analysis of electricity retailers based on cloud model and intuitionistic fuzzy analytic hierarchy process. Int J Energy Res 45:4285-4302. https://doi.org/ 10.1002/er.6090

Zahar Djordjevic M, Simeunovic B, Nestic S et al (2020) Study on performance evaluation of the production process - fuzzy MCDM approach. J Intell Fuzzy Syst 39:4009-4026. https://doi.org/10. 3233/jifs-200159

Zavala-Alcívar A, Verdecho MJ, Alfaro-Saiz JJ (2020) A conceptual framework to manage resilience and increase sustainability in the supply chain. Sustain 12:6300

Zhang Q, Huang Y (2012) Early warning index selection and weight assignment for city significant emergency in uncertain environment. Adv Inf Sci Serv Sci 4:490-497. https://doi.org/10.4156/ AISS.vol4.issue23.61

Zhixiong C, Juanping C, Jinsha Y et al (2019) Network access selection algorithm based on balanced profits between users and network. Wirel Commun Mob Comput. https://doi.org/10.1155/2019/ 6981657

Zimon D, Madzík P (2020) Standardized management systems and risk management in the supply chain. Int J Qual Reliab Manag 37:305-327. https://doi.org/10.1108/IJQRM-04-2019-0121

Zimon D, Madzik P, Sroufe R (2020) The influence of ISO 9001 \& ISO 14001 on sustainable supply chain management in the textile industry. Sustain 12:4282. https://doi.org/10.3390/su12104282

Publisher's Note Springer Nature remains neutral with regard to jurisdictional claims in published maps and institutional affiliations. 